\title{
Assessment of Hematological Scoring System (HSS) in Early Diagnosis of Neonatal Sepsis in Neonatal Intensive Care Units
}

\author{
Hisham A. Ismail ${ }^{1 *}$; Abd El Aziz, A. M. ${ }^{2}$; El Araby, H.A. ${ }^{2}$ and Wael S. Soliman1 ${ }^{1}$ \\ ${ }^{1}$ Molecular Diagnosis Department, Genetic Engineering and Biotechnology Research \\ Institute (GEBRI), Sadat City University, Egypt. \\ ${ }^{2}$ National Liver Institute, Menoufia University, Egypt. \\ Corresponding author; email; dr_hishamsadek@yahoo.com
}

\begin{abstract}
Although there have been several advancements in the diagnosis of neonatal sepsis, it still remains a major challenge, as there is no specific and sensitive marker for the timely diagnosis. Frequent incidence of noninfectious conditions that resemble to the clinical picture of neonatal sepsis, primarily in very low birth weight preterm infants, that complicates the identification of neonatal sepsis. The present study was undertaken to assess the significance of the hematological scoring system (HSS) for early detection of neonatal sepsis in total 42 cases with blood culture proven neonatal sepsis of 102 clinically diagnosed neonates admitted to the Neonatal Intensive Care Units (NICU) in El Menoufia and El Kalyoubia governorates hospitals versus 30 age matched healthy controls. The following HSS parameters were found to be significant for the early diagnosis of neonatal sepsis; Total WBC count, Total PMN count, Immature PMN count, I:T PMN ratio and Platelet count while the most sensitive parameters was degenerative changes and toxic granulation in PMNL.
\end{abstract}

Keywords: Neonatal sepsis; Hematologic Scoring System (HSS); BACT/ALERT automated blood culture system.

\section{INTRODUCTION}

Sepsis remains a major cause of morbidity and mortality during the first year of life. Sepsis is the sixth leading cause of death among neonates, and the eighth leading cause of death for infants during the first year of life (Heron, 2015). Neonatal sepsis is responsible for a high percentage of deaths in newborns. The fact that $75 \%$ of this mortality occurs in developing countries is due to under-recognition of illness (Obiero et al, 2015). Pathogens in blood culture are only detected in 25\% of cases(AlZahrani et al, 2015) and culture results take more than 48 h,( Tripathi \& Malik, 2010) thereby being less efficient as sepsis progression is rapid (Kumar \& Bhat, 2015). Basic hematological tests, such as $\mathrm{CBC}$, absolute neutrophil count (ANC), differential count, and immature to total leucocytes ratio (I/T), have been used for the diagnosis of neonatal sepsis although $\mathrm{CBC}$ has a poor predictive value (Shah \& Padbury, 2014). As the signs and symptoms of neonatal sepsis are nonspecific, usually a complete blood count $(\mathrm{CBC})$ is done to evaluate the likelihood of infection and need for antibiotics treatment (Mukhopadhyay \& Puopolo, 2012) Normal neutrophil values peak $\left(7800-14,500\right.$ cells/ $\mathrm{mm}^{3}$ ) during $12-14 \mathrm{~h}$ of age and decline (2700-13,000 cells/ $\mathrm{mm}^{3}$ ) during 72-240 $h$ of age (Simonsen et al, 2014). Rather than specifying a given range (or cut-off values) for $\mathrm{CBC}$, it is better to use agespecific likelihood ratios for $\mathrm{CBC}$ (Newman et al, 2010). I/T ratio of $>0.2$ 
suggests sepsis, whether $\mathrm{I} / \mathrm{T}$ ratios greater than 0.30 were associated with EOS (Kumar \& Bhat, 2015). When WBC count $(<5000)$ and ANC $(<1000)$ values were low, they were most predictive of infection (Mukhopadhyay \& Puopolo, 2012). In Europe, every year, 157000 people die for this systemic multi-organs failure as a consequence of bacterial or fungal infection (Goto \& Al-Hasan; 2013). Group B Streptococcus (GBS) remains the leading cause of EOS in term neonates, although the overall national incidence has decreased by $87 \%$ with the implementation of intra-partum antibiotic (IPA) for the prevention of early-onset GBS sepsis (Centers for Disease Control and Prevention, 2013). After the initiation of IPA for GBS, Escherichia coli has emerged as the leading cause of EOS in preterm neonates (Kumar \& Bhat, 2015).

After GBS, the other prevalent grampositive organisms causing neonatal sepsis include Staphylococcus aureus, coagulase- negative Staphylococcus (CoNS), Enterococcus, and Listeria mono- cytogenes. Other than E. coli, the most common gram-negative organisms are Klebsiella, Enterobacter, Citrobacter, and Pseudomonas (Kumar \& Bhat, 2015).

\section{MATERIAL AND METHODS}

This study was conducted on 102 neonates suspected to have clinically diagnosed neonatal sepsis admitted to Neonatal Intensive Care Units (NICUs) in 4 distinct hospitals from Menoufia and El Kalyoubia governorates were enrolled. These NICUs and corresponding patients' number were:-

1- Neonatal intensive care unit (NICU), National Liver Institute hospital- Menoufia University, from which 24 cases were included.

Table (1): Hematological scoring system.
2- Neonatal intensive care unit (NICU), Menoufia University hospital, from which 41 cases were included.

3- Neonatal intensive care unit (NICU), Benha University hospital, from which 30 cases were included

4- Neonatal intensive care unit (NICU), Berket El Saba central hospital - Ministry of Health and Population, from which 7 cases were included.

These patients were evaluated for the following seven CBC parameters; (HSS parameters):- total WBC count, total PMN count, immature PMN count, platelets count, degenerative changes in PMN leucocytes (toxic granules and cytoplasmic vacuoles), I/T ratio and I/M ratio.

The sepsis work up was done including routine blood counts along with the HSS value.

The clinical diagnosis of neonatal sepsis dependent on positivity of at least two of the following laboratory screening tests to identify neonates with clinical neonatal septicemia.

The investigations are:-

i. Total leucocytic count $<5000 / \mathrm{mm} 3$ or $\geq 25,000$ at birth or $\geq 30,000$ $12-24 \mathrm{~h}$ or $\geq 21,000$-Day 2 onwards.

ii. Band cell count $\geq 20 \%$

iii. Micro ESR $\geq 15 \mathrm{~mm} / 1^{\text {st }}$ hour

iv. C-reactive protein $>6 \mathrm{mg} / \mathrm{dL}$

v. Absolute neutrophil count $<1500 / \mathrm{mm}^{3}$

The clinically diagnosed cases with neonatal sepsis will be undergone conventional blood culture test with automated $\quad$ BACT/ALERT $^{\circledR} \quad$ 3D 60 instrument (BioMérieux, INC. USA) blood culture system to confirm the diagnosis of neonatal sepsis. 


\begin{tabular}{|l||l||l||}
\hline Criteria & Abnormality & Score \\
\hline \hline Total WBC count & $\leq 5,000 / \mu$ l & 1 \\
& $\geq 25,000$ at birth & 1 \\
& $\geq 30,000-12-24 \mathrm{~h}$ & \\
Total PMN count & $\geq 21,000-$ Day 2 onwards & \\
& No mature PMN seen & 2 \\
Immature PMN count & Increased/decreased & 1 \\
I:T PMN ratio & Increased & 1 \\
I:M PMN ratio & Increased & 1 \\
Degenerative changes in PMN & $\geq 0.3$ & 1 \\
& Toxic granules/cytoplasmic vacuoles & \\
Platelet count & $\leq 150,000 /$ mm3 & \\
\hline
\end{tabular}

The normal values are

Total PMN count - 1800-5400/mm3

Immature: Total PMN ratio- 0.120

Immature PMN count $-600 / \mathrm{mm} 3$

Immature: Mature PMN ratio $-\geq 0.3$

Table (2): Interpretation of hematological scoring system.

\begin{tabular}{|l|l||}
\hline Score & Interpretation \\
\hline \hline$\leq 2$ & Sepsis is unlikely \\
3 or 4 & Sepsis is possible \\
$\geq 4$ & Sepsis or infection is very likely \\
\hline
\end{tabular}




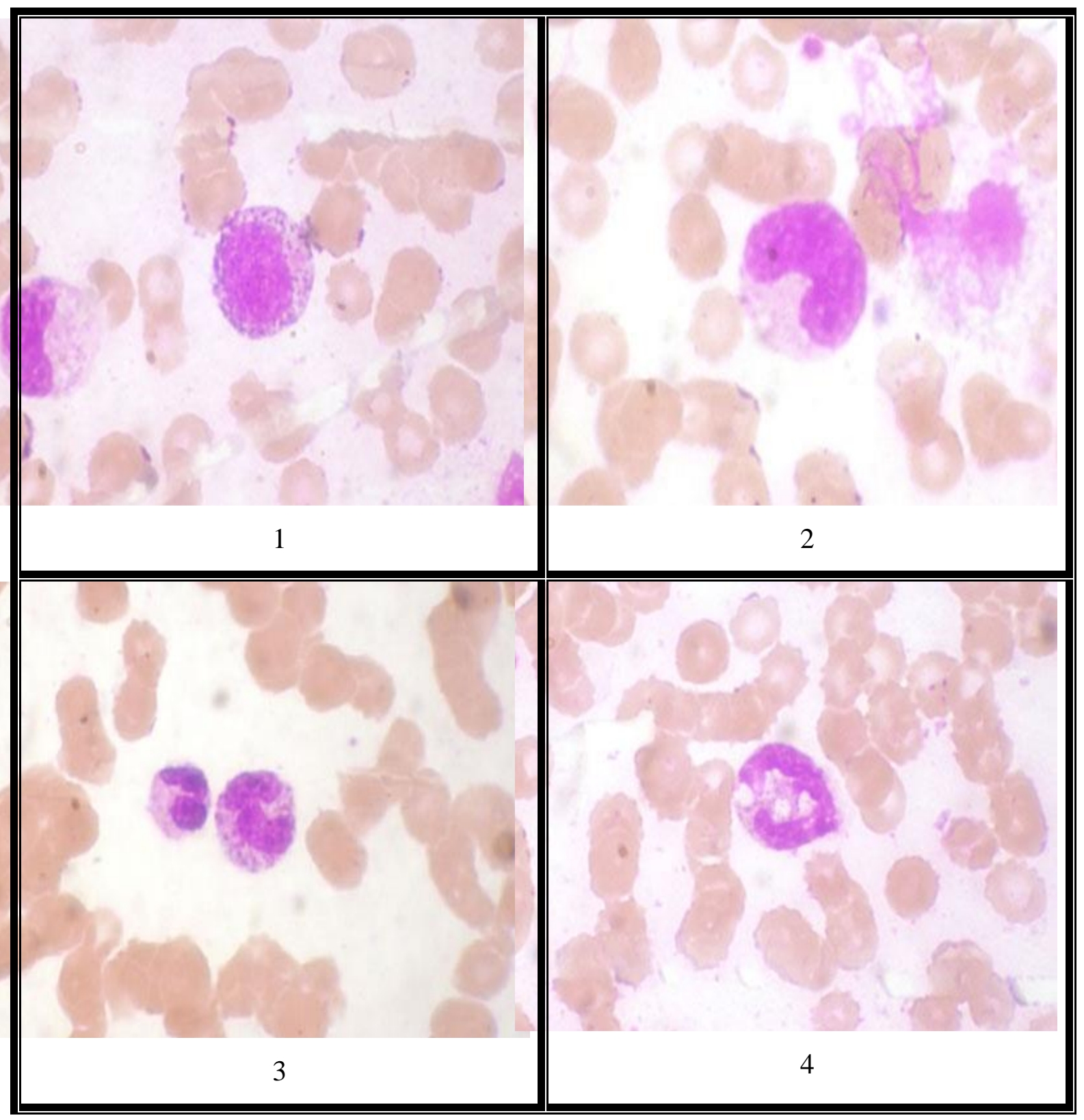

(Leishman, x1000)

Figure (1): Photomicrograph of neutrophils differentiation and abnormalities.

1- Immature neutrophils(Promyelocyte and Myelocyte) 3- Neutrophils with toxic granules

\section{2- Band form}

\section{Results}

In this study, from 102 clinically diagnosed neonatal sepsis, 42 cases were blood culture proven bacterial neonatal sepsis confirmed with the detection of bacterial growth with BACT/ALERT automated blood culture system. Table (3) represents

\section{4- Neutrophil with cytoplasmic} vacuoles

types of bacteria detected with conventional blood culture method in 42 neonates out of 102 clinically diagnosed neonatal sepsis patients. Table (2) shows profile of HSS distribution in 42 blood culture proven neonatal sepsis patients. 
Table (3): Bacteria and isolated with BACT/ ALERT automated blood culture system.

\begin{tabular}{||l||c||c|}
\hline \multicolumn{1}{|c||}{ Organisms } & No & percent \\
\hline \hline 1- Bacterial & 20 & $47.6 \%$ \\
Klebsiella & 5 & $11.9 \%$ \\
Staphylococcus aureus & & \\
Coagulase negative staphylococcus & & \\
(CoNs) & 3 & $7.1 \%$ \\
- Staphylococcus epidermedis & 2 & $4.8 \%$ \\
- CoNS & 1 & $2.4 \%$ \\
- Staphylococcus lugdunensis & 1 & $2.4 \%$ \\
Streptococcus & 2 & $4.8 \%$ \\
E coli & 3 & $7.1 \%$ \\
Enterococci & 4 & $9.5 \%$ \\
Enterobacter & 1 & $2.4 \%$ \\
Acinatobacter & 42 & $100 \%$ \\
\hline \hline
\end{tabular}

Table (4): Profile of hematological scoring system in blood culture proven sepsis subgroup.

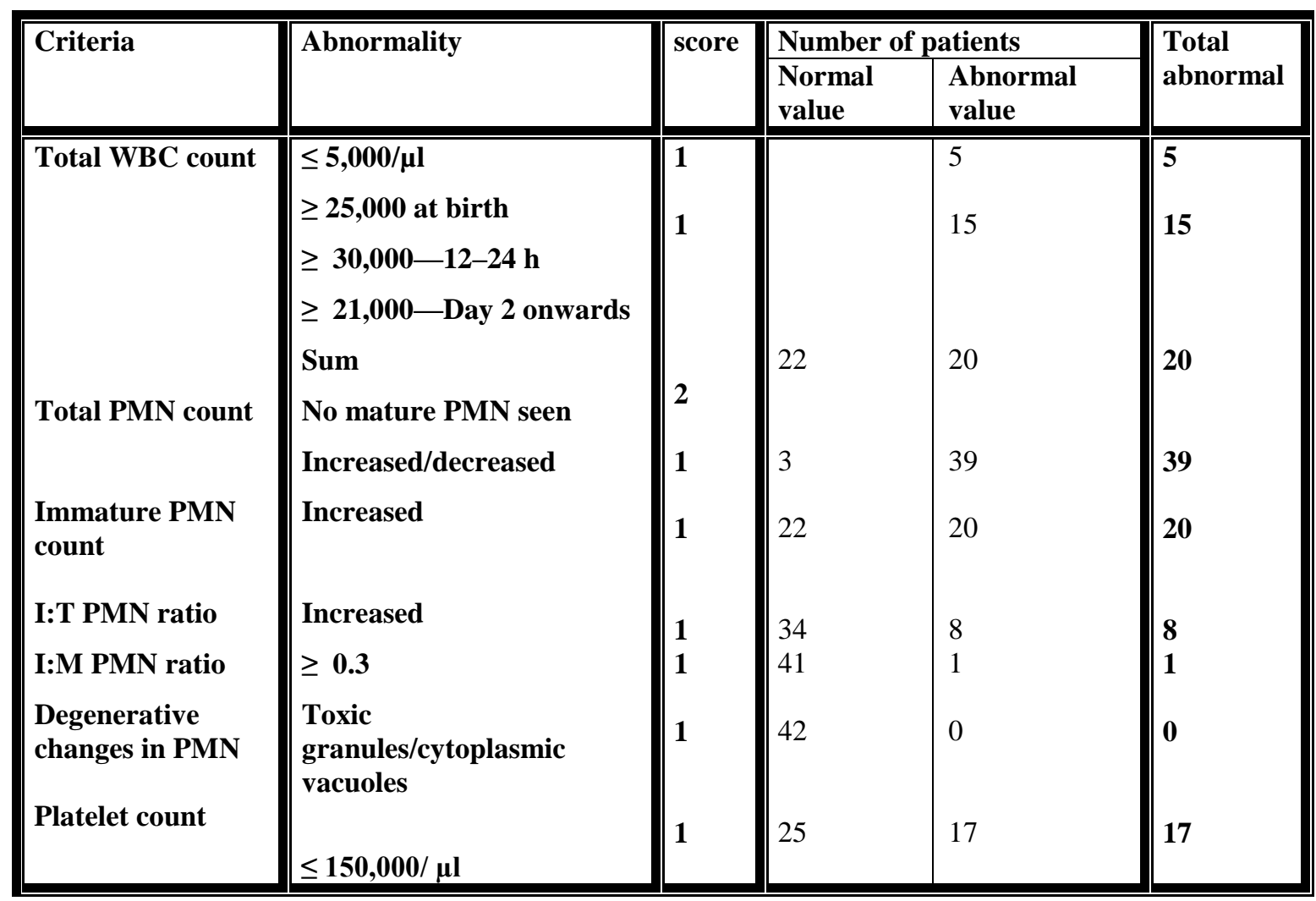


Table (5): Statistics of hematological scoring system parameters in blood culture proven sepsis subgroup.

\begin{tabular}{|c|c|c|c|c|}
\hline Parameter & Value & $\begin{array}{l}\text { Cases } \\
(n=42)\end{array}$ & $\begin{array}{c}\begin{array}{c}\text { Control } \\
(\mathbf{n}=30)\end{array} \\
\end{array}$ & $\begin{array}{l}\begin{array}{l}\text { Statistical } \\
\text { significance }\end{array} \\
\end{array}$ \\
\hline Mean \pm SD & $\begin{array}{l}\text { Normal } \\
\text { Abnormal }\end{array}$ & $\begin{array}{l}22 \\
20 \\
17384 \pm 9012\end{array}$ & $\begin{array}{l}28 \\
2 \\
10811 \pm 5206\end{array}$ & $\begin{array}{l}P=0.0002 \\
P=0.0006\end{array}$ \\
\hline $\begin{array}{l}\text { Total PMN count } \\
(<1800 / \mu \mathrm{l} \text { or }>5400 / \mu \mathrm{l}) \\
\text { Mean } \pm \text { SD }\end{array}$ & $\begin{array}{l}\text { Normal } \\
\text { Abnormal }\end{array}$ & $\begin{array}{l}3 \\
39 \\
10373 \pm 6673\end{array}$ & $\begin{array}{l}21 \\
9 \\
5383 \pm 2928\end{array}$ & $\begin{array}{l}P<0.0001 \\
P<0.0001\end{array}$ \\
\hline $\begin{array}{l}\text { Immature PMN count } \\
(>600 / \mu \mathrm{l})\end{array}$ & $\begin{array}{l}\text { Normal } \\
\text { Abnormal }\end{array}$ & $\begin{array}{l}22 \\
20 \\
857 \pm 1024\end{array}$ & $\begin{array}{l}29 \\
1 \\
209 \pm 163\end{array}$ & $\begin{array}{l}P=0.0002 \\
P=0.001\end{array}$ \\
\hline Mean \pm SD & & & & \\
\hline $\begin{array}{l}\text { I:T PMN ratio } \\
(>0.12)\end{array}$ & $\begin{array}{l}\leq 0.12 \\
>0.12 \\
\end{array}$ & $\begin{array}{l}34 \\
8 \\
\end{array}$ & $\begin{array}{l}29 \\
1 \\
\end{array}$ & $P=0.04$ \\
\hline $\begin{array}{l}\text { I:M PMN ratio } \\
(\geq 0.3)\end{array}$ & $\begin{array}{l}<0.3 \\
\geq 0.3\end{array}$ & $\begin{array}{l}41 \\
1\end{array}$ & $\begin{array}{l}30 \\
0\end{array}$ & $P=0.14$ \\
\hline $\begin{array}{l}\text { Degenerative changes in } \\
\text { PMN }\end{array}$ & $\begin{array}{l}\text { Absent } \\
\text { Present }\end{array}$ & $\begin{array}{l}42 \\
0\end{array}$ & $\begin{array}{l}30 \\
0\end{array}$ & $P=0.00$ \\
\hline $\begin{array}{l}\text { Platelet count } \\
(<150000 / \mu \mathrm{l}) \\
\text { Mean } \pm \text { SD }\end{array}$ & $\begin{array}{l}\geq 150000 / \mu 1 \\
<150000 / \mu 1\end{array}$ & $\begin{array}{l}25 \\
17 \\
200761 \pm 137851\end{array}$ & $\begin{array}{l}29 \\
1 \\
304500 \pm 123120\end{array}$ & $\begin{array}{l}P=0.0003 \\
P=0.001\end{array}$ \\
\hline $\begin{array}{l}\text { HSS } \\
\text { Mean } \pm \text { SD }\end{array}$ & $\begin{array}{l}<3 \\
\geq 3\end{array}$ & $\begin{array}{l}20 \\
22 \\
2.5 \pm 1.29\end{array}$ & $\begin{array}{l}29 \\
1 \\
0.47 \pm 0.68\end{array}$ & $\begin{array}{l}\mathrm{P}<0.0001 \\
\mathrm{P}<0.0001\end{array}$ \\
\hline
\end{tabular}


Table (6): Sensitivity and specificity with positive and negative predictive values of hematological scoring system in blood culture proven sepsis subgroup.

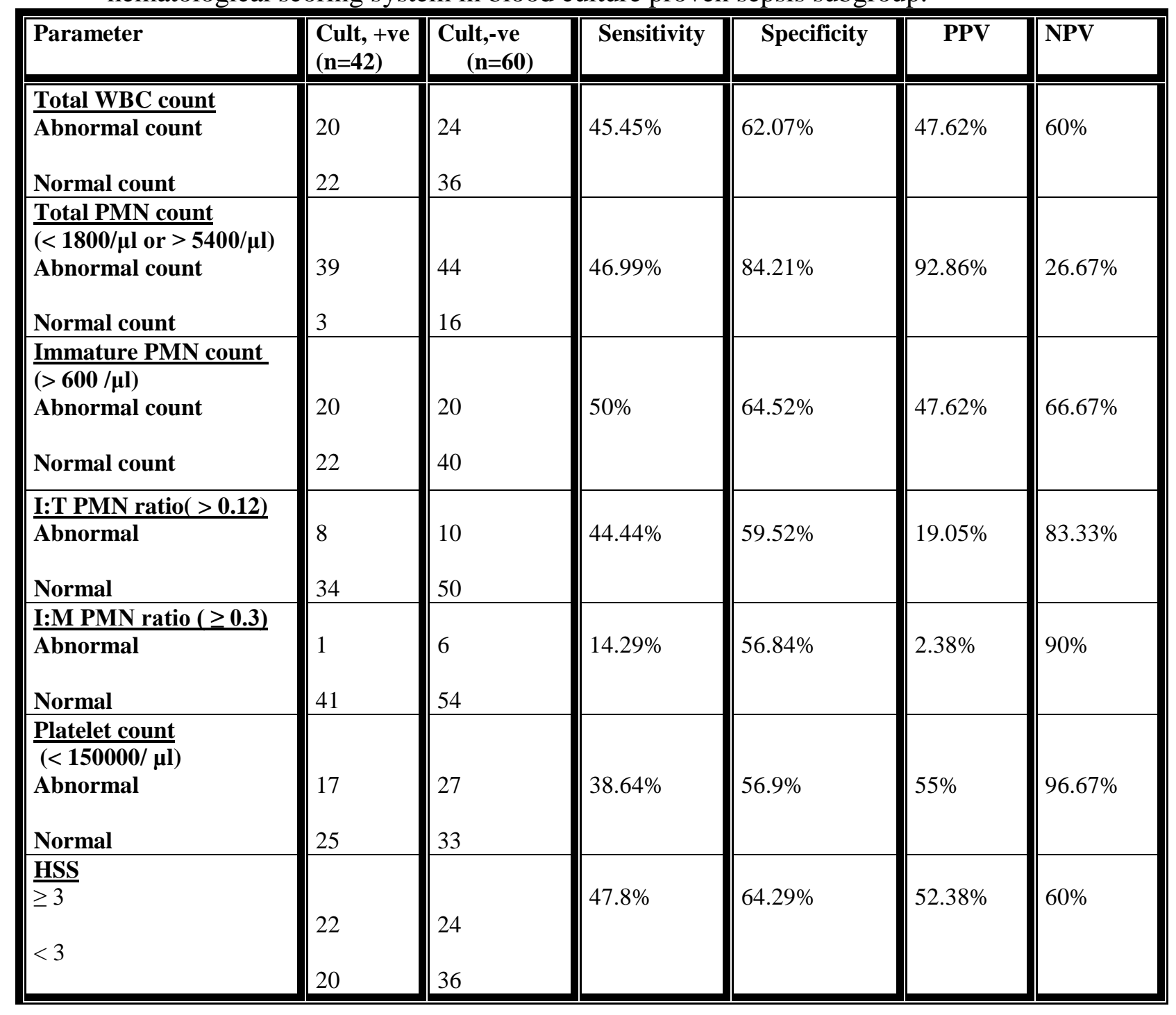

Table (5) represents statistical significance of HSS parameters in 42 blood culture proven neonatal sepsis patients. Which shows statistical significant difference between blood culture proven sepsis and control group in the following parameters including its mean \pm SD:-

Total WBC count, total polymorph nuclear leucocytes (PMNL), immature polymorph nuclear leucocytes, platelets count and HSS. Whether statistical significance present between two groups in I:T $\mathrm{PMN}$ ratio (> 0.12). Table (6) represents sensitivity and specificity in addition to positive and negative predictive values for different HSS parameters. 


\section{Discussion}

Hematologic scoring system (HSS) can improve the diagnostic accuracy of diagnosing neonatal sepsis (Narasimha \& Kumar, 2011).

Our study was designed to detect the ability of hematological scoring system (HSS) in early diagnosis of neonatal sepsis. And try to prove that, HSS is a simple, quick, cost effective tool which can be used as a screening test for early diagnosis of neonatal sepsis. From 102 clinically diagnosed neonatal sepsis patients blood culture proven neonatal sepsis were detected in 42 cases. The bacteria which were isolated and its corresponding cases numbers were shown in Table (1).

In this study, there were 7 hematologic parameters and indices were evaluated in HSS which include; total WBC count, total PMN count, immature PMN count, platelet count, degenerative changes in PMN cells (toxic granulations and cytoplasmic vacuoles), I/T ratio and I/M ratio. Total WBC count and its mean \pm SD show statistical significance difference in blood culture proven sepsis group than control group. It has low sensitivity and PPV but to some extent moderate specificity and NPV. Low sensitivity for total WBC match the results of one study done by Narasimha and Kumar who found the sensitivity of total WBC count was $10.52 \%$ while the specificity was $91.66 \%$ the PPV and NPV in the same were $80 \%$ and $24.44 \%$ respectively for the diagnosis of neonatal sepsis (Narasimha \& Kumar,2011). In another study by Shirazi et al., that evaluate the hematological profile of neonatal sepsis they found the sensitivity of total WBC count was $35 \%$ and specificity was $77 \%$ for neonatal sepsis diagnosis (Shirazi et al, 2010). Total PMN count and its mean \pm SD show statistical significance for the diagnosis of neonatal sepsis. It has a sensitivity of $46.99 \%$ for the diagnosis of neonatal sepsis and specificity of $84.21 \%$. The PPV and NPV for PMN count for the diagnosis of neonatal sepsis was $92.86 \%$ and $26.67 \%$ respectively. Narasimha and Kumar reported high sensitivity and PPV for total PMN count in the diagnosis of neonatal sepsis; $89.47 \%$ and $75.55 \%$ respectively (Narasimha \& Kumar, 2011). In accordance with large number of studies who have observed that the total leucocytic count or the total neutrophil count show no significant association with sepsis. It should not be deceived by neutrophil count alone without noting alteration in the ratio of mature and immature neutrophils (Shirazi et al, 2010). Immature PMN count and its mean \pm SD show statistical significance for the diagnosis of neonatal 
sepsis. it has moderate specificity and NPV; $64.52 \%$ and $66.67 \%$ respectively. Immature circulating neutrophils, known as band cells, appear in peripheral blood in response to infection (Bedford Russell, 2015). Narasimha and Kumar reported high sensitivity and PPV for immature PMN count for the diagnosis of neonatal sepsis; $78.94 \%$ and $73.17 \%$ respectively (Narasimha \& Kumar, 2011). Platelets count and its mean \pm SD show statistical significance for the diagnosis of neonatal sepsis. it has high NPV for the exclusion of neonatal infections. Thrombocytopenia is a common feature of generalized infection and necrotising enterocolitis (NEC), but is also a feature of non-infective disorders such as hypoxic ischaemic encephalopathy (Bedford Russell, 2015).It characterized by poor sensitivity and specificity for the diagnosis of neonatal sepsis and are unreliable diagnostic parameter for initiating or discontinuing antibiotics (Manzoni et al, 2009). Narasimha and Kumar reported high specificity and PPV for platelets count in the diagnosis of neonatal sepsis; $75 \%$ and $85.71 \%$ respectively (Narasimha \& Kumar,2011). Shirazi et al, found the sensitivity of platelets count was $61 \%$ and specificity was $82 \%$ for neonatal sepsis diagnosis (Shirazi et al, 2010). $\mathrm{I} / \mathrm{T}$ ratio show statistical significance for the diagnosis of neonatal sepsis. It has high NPV for the exclusion of neonatal infection $(83.33 \%)$. I/T ratio of $>0.2$ is highly suspicious for neonatal sepsis (Bedford Russell, 2015). High immature-to-total neutrophil ratio (I:T ratio) were associated with increasing odds of infection,; however, the test sensitivities for detection of sepsis were low (Hornik et al, 2012). Narasimha and Kumar reported high PPV for I/T ratio for the diagnosis of neonatal sepsis $88.88 \%$ (Narasimha \& Kumar, 2011). $\mathrm{I} / \mathrm{M}$ ratio show no statistical significance for the diagnosis of neonatal sepsis. it has high NPV for the exclusion of neonatal infection (90\%). Narasimha and Kumar reported high sensitivity and PPV for immature PMN count for the diagnosis of neonatal sepsis; $73.68 \%$ and $82.35 \%$ respectively (Narasimha $\&$ Kumar, 2011).

\section{Conclusions}

In this study, the HSS was statistically significant test for the early diagnosis of neonatal sepsis. It is a useful preliminary screening test for early detection of neonates with sepsis with good negative predictive values. 


\section{References}

- Al-Zahrani A, Ghonaim M, Hussein Y, Eed

E, Khalifa A, Dorgham L. Evaluation of recent methods versus conventional methods for diagnosis of early-onset neonatal sepsis. J Infect Dev Ctries 2015;9: 388-393.

-Bedford Russell A R. Neonatal sepsis. Pediatrics and child health 2015; 25(6):271275.

- Centers for Disease Control and Prevention. Active bacterial core surveillance report, emerging infections program network, group B Streptococcus, 2013. Available at: http://www. cdc.gov/abcs/reportsfindings/survreports/gbs13.pdf Accessed 1124-2015.

- Hornik CP, Benjamin DK, Becker KC, et al. Use of the complete blood cell count in early-onset neonatal sepsis. Pediatr Infect Dis J 2012; 31:799-802. [PubMed: 22531231]

- Heron M. Deaths: leading causes for 2011. Nat Vital Stat Rep 2015; 64:1-95.

- Kumar K M, Bhat B V. Current challenges and future perspectives in neonatal sepsis. Pediatric infectious disease 2015 ; 7: 41 46.

- Manzoni P, Rinaldi M, Cattani S, et al. Italian Task Force for the Study and Prevention of Neonatal Fungal Infections, Italian Society of Neonatology. Bovine lactoferrin supplementation for prevention of late-onset sepsis in very low-birth-weight neonates: a randomized trial. JAMA 2009; 302(13):1421-1428.
- Mukhopadhyay S, Puopolo KM. Risk assessment in neonatal early onset sepsis. Semin Perinatol 2012; 36:408-415.

- Narasimha A and Kumar M H. Significance of Hematological Scoring System (HSS) in Early Diagnosis of Neonatal Sepsis. Indian J Hematol Blood Transfus 2011; 27(1):14-17.

- Newman TB, Puopolo KM, Wi S, Draper D, Escobar GJ. Interpreting complete blood counts soon after birth in newborns at risk for sepsis. Pediatrics 2010;126:903-909.

- Obiero CW, Seale AC, Berkley JA. Empiric treatment of neonatal sepsis in developing countries. Pediatr Infect Dis J 2015; 34:659661.

- Shah BA, Padbury JF. Neonatal sepsis: an old problem with new insights. Virulence 2014;5: 170-178.

- Shirazi H, Riaz S, Tahir R. Role of the Hematological Profile in Early Diagnosis of Neonatal Sepsis. Ann Pak Inst Med Sci; 2010; 6(3): 152-156.

- Simonsen K, Anderson-Berry A, Delair S, Davies HD. Earlyonset neonatal sepsis. Clin Microbiol Rev 2014; 27 :21-47.

- Tripathi S, Malik G. Neonatal sepsis: past, present and future; a review article. Internet J Med Update. 2010;5:45-54.

-Weston EJ, Pondo T, Lewis MM, et al. The burden of invasive early-onset neonatal sepsis in the United States, 2005-2008. Pediatr Infect Dis J 2011; 30:937-41. 